\title{
Identification of the Cause of Damage to the Firefighter Ladder
}

Filip Průša ${ }^{1}$, Vít Jonák ${ }^{1}$, Angelina Strakošová ${ }^{1}$, Karel Doubrava ${ }^{2}$, Miroslav Španiel ${ }^{2}$, Václav Vystrčil ${ }^{3}$, Dalibor Vojtěch ${ }^{1}$

${ }^{1}$ Faculty of Chemistry and Technology, University of Chemistry and Technology Prague, Technicka 5, 16628 Prague 6. Czech Republic. E-mail: prusaf@vscht.cz

${ }^{2}$ Department of Mechanics, Biomechanics and Mechatronics, Faculty of Mechanical Engineering, Center of Advanced Aerospace Technology, Czech Technical University in Prague, Technicka 4, 16607 Prague 6. Czech Republic.

${ }^{3}$ Technical Institute of Fire Protection in Prague, Fire Rescue Service of the Czech Republic, Piskova 42, 14300 Prague 4. Czech Republic

Two extendable firefighter ladders, both made of AA 6063 alloy, has been destructively tested accordingly to the ČSN EN ISO 1147 to determine the maximal load before their failure. For this purpose, two brand new ladders with a complex profile were compared to the 5 -year old one with a far simpler profile. It was found, that the new ladder broke already at a load of $366(365 \mathrm{~kg})$ while the 5-year old ladder could withstand a much higher load of $426 \mathrm{~kg}$. Since both the ladders broke nearby the guides acting as a mechanical support for their extension, it was of high interest to investigate the cause of different behaviour. Considering the fact, that the brand new ladder had a much more complex profile of the beam and the fact, that the guides were welded to the beams, it was of high importance to investigate the influence of the weld on the overall integrity of the ladder. It was found, that the weld itself deteriorated the mechanical properties of the beam reaching the minimal hardness in the distance of $10 \mathrm{~mm}$, which also corresponded with the crack initiation site. This place also showed the lowest hardness reaching only 52 HV 1.

Keywords: AA 6063, microstructure, weld joint, failure, mechanical properties.

\section{Introduction}

The firefighter ladders belong to the essential equipment of each firefighter department and thus undergone some extensive development during the past decades. Firstly, the ladders were made of wood which was the easiest material for processing and manufacturing of the ladders. With the increasing demands, the wood ladders were slowly replaced with steel that offered significantly better mechanical properties and durability. However, the steel ladders were, although their possessed compact dimensions, heavier limiting theirs use especially in difficult environments including dense vegetation, steep slopes and situations where the ladder needed to be precisely moved to be placed in a particular position [1]. Therefore, the ladders are nowadays manufactured from aluminium alloys which in general offers low density, good strengthto-weight ratio and appropriate corrosion resistence [2-16]. Particularly, the AA 6063 alloy offers the best combination of mechanical properties, good extrudability while maintaining low density $[1,17]$.

Usually, each part of the ladder is made by hot extrusion for which a cylindrical billet of AA 6063 alloy is preheated for the extrusion temperature, extruded through a die and then quenched in water. Afterwards, the extruded materials are stretched to relieve the thermally induced stresses within the material and to increase the straightness. The extruded materials are then cut into easily manageable pieces and subjected to ageing to increase the strength of the material. During the process, precipitation of $\mathrm{Mg}_{2} \mathrm{Si}$ particles as well as the growth of the $\mathrm{Al}(\mathrm{Fe}, \mathrm{Si}) \mathrm{Mn}$ phases, both with appropriate dimensions, is observed and the process is complete in a few hours to provide the maxima of desired properties. However, further coarsening of these particles as well as of the $\alpha$-Al grains continues as the alloy is exposed to elevated temperatures. This results in a decrease of the properties making use of such materials as for firefighter ladders extremely risky. Thus, considering the safety of the firefighters, the profile of the beam itself and the mounting strategy of the guides used for extensions is critical.

In this work, two extendable firefighter ladders were destructively investigated to determine which of them would perform better during the three-point bending test. It was found, that attaching the guide to the beam by welding significantly weakens the mechanical properties of the ladder itself which can withstand a load of only $365 \mathrm{~kg}$. 


\section{Experimental}

Two different types of extendable firefighter ladders were used to investigate the influence of different beam profile and different guide mounting technique (welded, riveted) on the mechanical properties (Fig. 1).
For this purpose, two brand new ladders (further denoted as ladder no. 1) with complex beam profile and welded guides were purchased (Fig. 1a). As a comparison, the results of this ladder were compared to a 5year old, yet non-used ladder (further denoted as ladder no. 2), characterized by a much simpler profile and riveted guides (Fig. 1b).

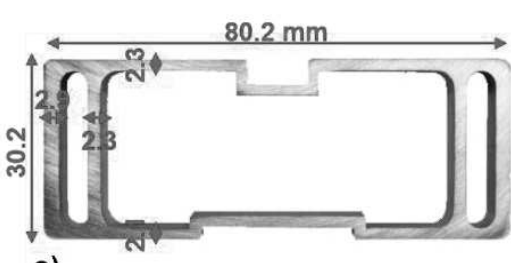

a)

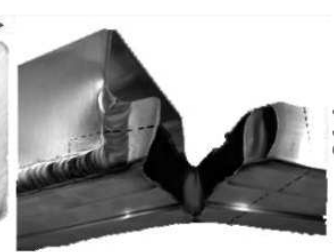

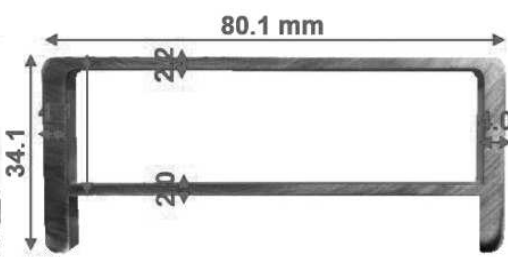

b)

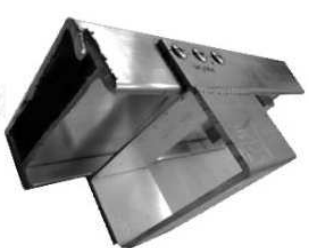

Fig. 1 Complex overview of both the tested ladders showing: a) brand new piece with complex profile and welded guides (ladder no. 1); b) 5-year old ladder with guides attached via rivets (ladder no. 2)

The ladders were destructively tested accordingly to the ČSN EN ISO 1147 as is shown in Fig. 2, where both sides were placed on a rigid supports (one static and one mobile to compensate for the movement of the ladder during the test). The method has been slightly modified to suppress any unnecessary impact load. This was achieved via a gradual filling of the water bags using flow meters. The weight applied on the ladder was determined using strain gauges attached between straps and the ladder.

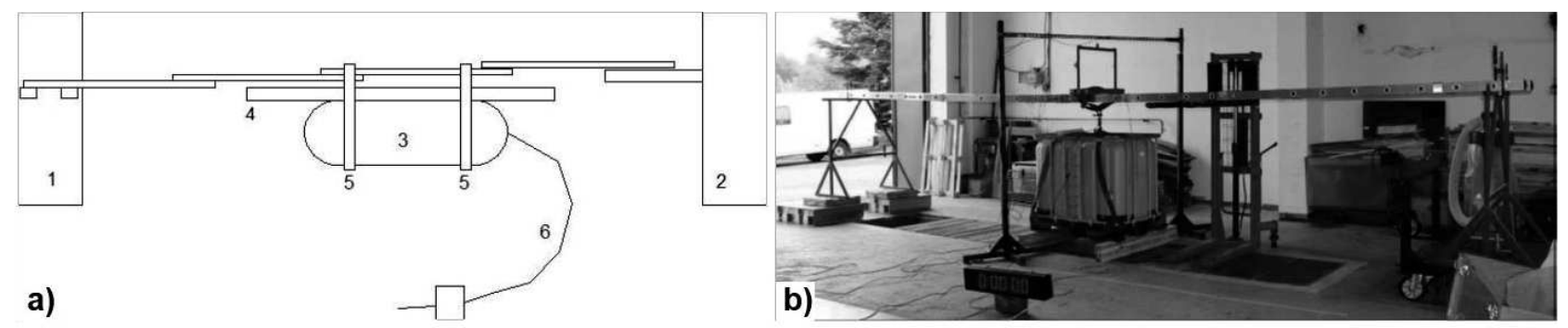

Fig. 2 Scheme of the testing set-up showing: a) schematic drawing (1,2 - supports; 3 - water bag; 4 - protective pad; 5 - straps; 6 - water inlet with flow meter); b) real set-up used for the testing

The bags were continuously filled with water and the ladder sag was measured at different moments of the test. It was found, that, against the presumptions, both the ladders no. 1 made of much more complex beams could withstand significantly lower load compared to the ladder no. 2. Therefore, the ladder no. 1 were examined for microstructure including optical microscopy (OM, Olympus PME-3) and scanning electron microscopy (SEM, Tescan Vega 3-LMU) equipped with energy dispersive spectroscopy (EDS, Oxford INCA $20 \mathrm{~mm}^{2}$ ) detector used for chemical microanalysis of present phases. The beam profile and profile across the weld zone was also examined for hardness change using Vickers indentor and load of 1 $\mathrm{kg}$. Each particular place on the beam, weld and guide was measured three times maintaining the distance between each measurement at least 3 times the length of the indent diagonal.

The chemical composition of both the tested ladders was determined by the glow-discharge optical emission spectroscopy (GDOES, Horriba JobinYvon GD Profiler II) and compared with the nominal composition given by the EN AW 6063 norm. Each ladder was measured on two different places for a total of 6 measurements which results are shown in Tab. 1.

Tab. 1 Chemical compositions of both tested ladders determined by GDOES analysis and their comparison with the nominal composition given by $E N A W 6063$

\begin{tabular}{lcccccc}
\hline Element concentration (wt.\%) & $\mathbf{M g}$ & $\mathbf{S i}$ & $\mathbf{F e}$ & $\mathbf{M n}$ & $\mathbf{T i}$ & $\mathbf{A l}$ \\
\hline Ladder no. 1 & 0.42 & 0.37 & 0.20 & 0.05 & 0.02 & bal. \\
\hline Ladder no. 2 & 0.47 & 0.37 & 0.20 & 0.04 & 0.02 & bal. \\
\hline Nominal composition of AA6063 & $0.45-0.90$ & $0.20-0.60$ & max. 0.35 & max 0.1 & max 0.1 & bal. \\
\hline
\end{tabular}




\section{Results and discussion}

\subsection{Mechanical testing}

Both the ladders were tested accordingly to the prescriptions stated in the CSN EN ISO 1147 as is shown in Fig. 3a,c. The water bags were gradually filled with water and the ladder sag was measured during the filling. It was found that the brand new ladder no. 1 exhibited $90 \mathrm{~cm}$ deep sag $33 \mathrm{~s}$ before breaking (see Fig. 3b). The test was repeated on the second identical ladder reaching highly comparable results achieving a maximum load of 366 and $365 \mathrm{~kg}$. On the other hand, the 5-year old ladder no. 2, with a much simpler beam profile, showed smaller sag withstanding a significantly higher load of $426 \mathrm{~kg}$ (Fig. 3d).

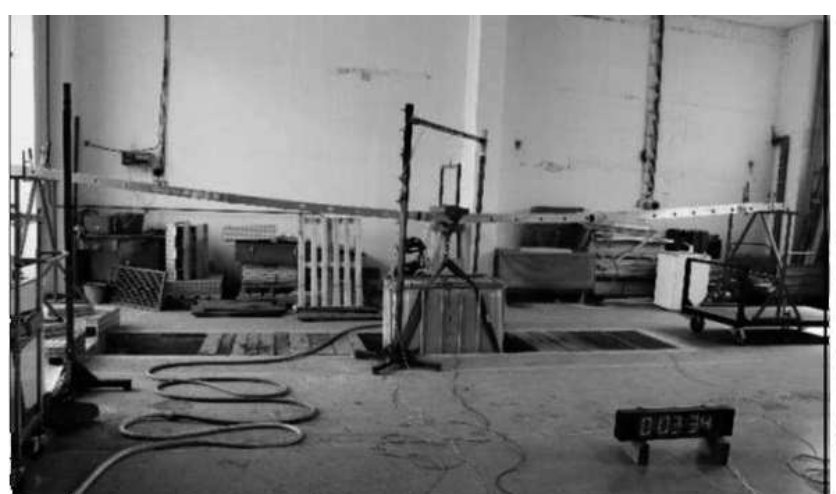

a)
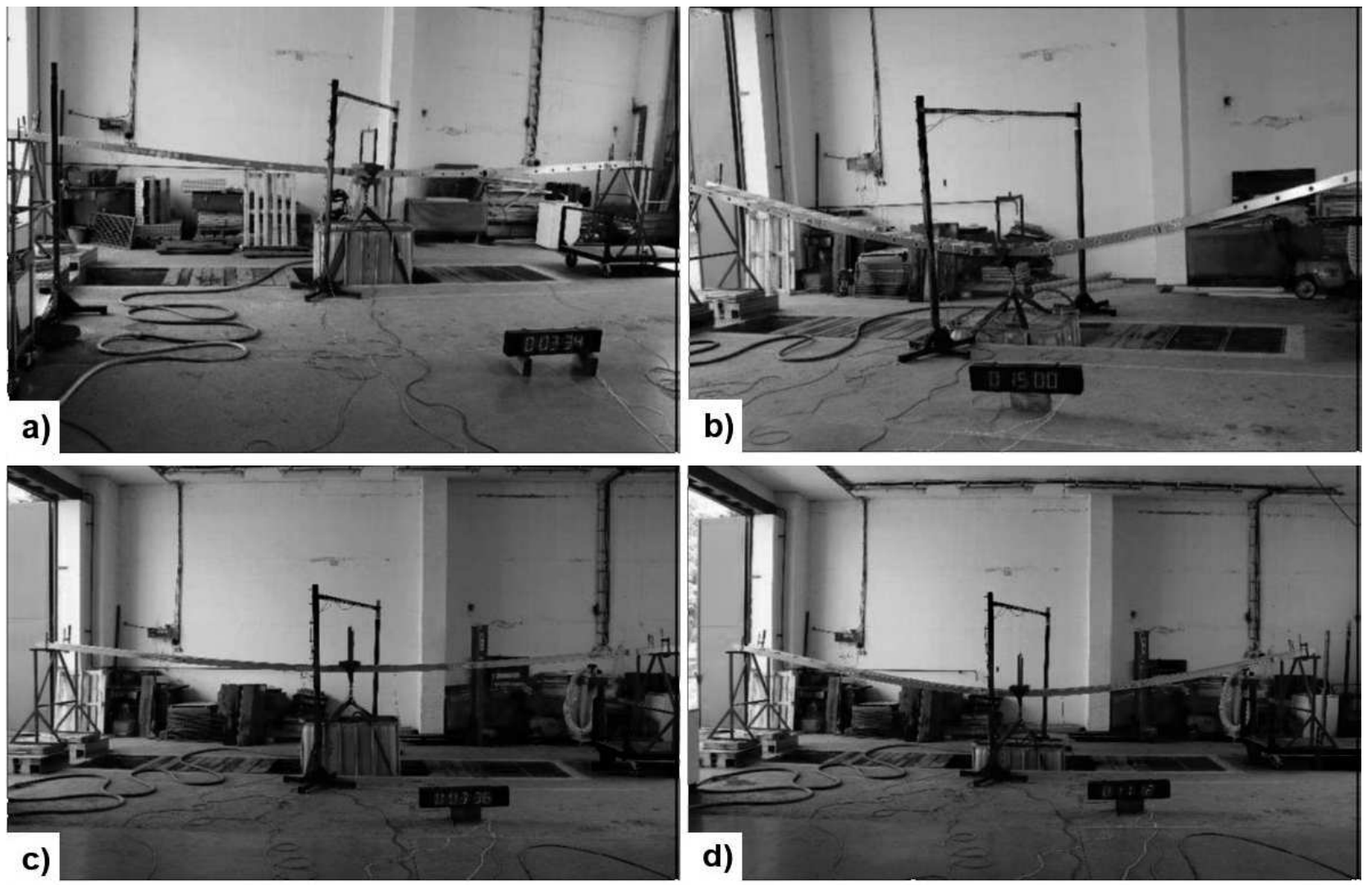

Fig. 3 The experimental setup used for destructive testing of the extendable firefighter ladders showing: a,b) ladder no. 1 at different stages of the test; $c, d)$ ladder no. 2 at different stages of the test

The ladders were cut to extract the area around the cracks as is shown in detail in Fig. 4. One can see, that the ladder no. 1 initiated the crack approximately 10 $\mathrm{mm}$ from the weld (see Fig. 4a). This corresponds with the area which was thermally affected due to the welding of the guides on beams. On the other hand, the ladder no. 2 cracked in the closest proximity of the riveted guide leaving the rivets on its place. Considering the experimental setup, the maxima of shear force could be expected to form right on the edge of the mounting guide which corresponds with the result shown in the case of ladder no. 2. However, both the tested ladders no. 1 showed initiation of the crack 10 $\mathrm{mm}$ from the weld bead edge pointing on a highly localized change in mechanical properties in this area due to thermally-related effects including grain, precipitates and secondary phase coarsening.

Thus, the ladder no. 1 was investigated to determine the major difference in the results since the presumptions based on the beams profile should deliver much better results compared to that observed. The fracture surface was extracted from the broken piece as is marked in Fig. 4a (area B) to be investigated using SEM. On the left side (Fig. 5), the initiation of the crack occurred which was confirmed by a presence of equiaxed dimples corresponding to a plastic deformation along this area. Moreover, some dimples also show in its centre a presence of secondary intermetallic particles, which were identified as $\mathrm{Al}(\mathrm{Fe}, \mathrm{Si}) \mathrm{Mn}$. As the crack continuously growth, the morphology of the fracture surface changes slightly showing also a presence of cleavage steps suggesting an increasing ratio of brittle behaviour within the material. This corresponds with the speed of the crack propagation and is confirmed by a steady increase in the content of facets. The rest of the material shows strictly a brittle morphology of the fracture surface without any traces of dimples corresponding to a fast termination of the crack growth. 


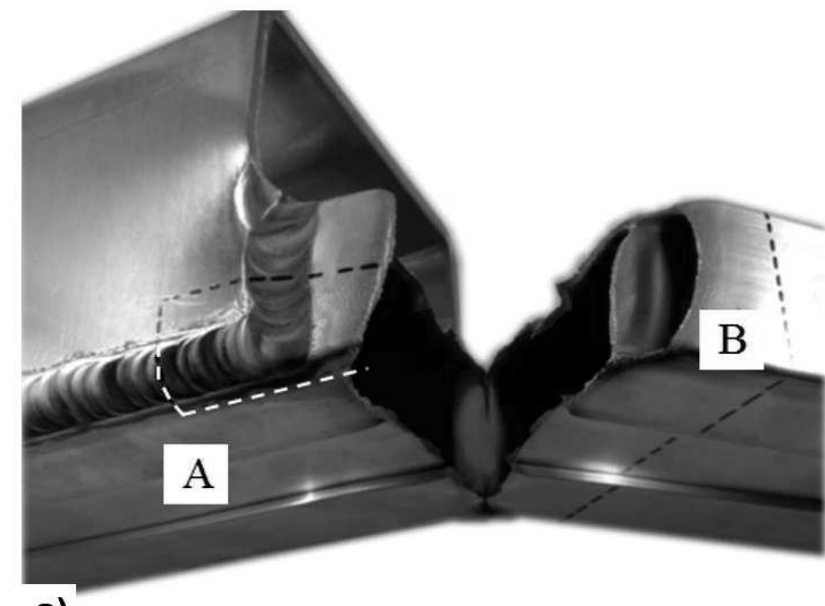

a)

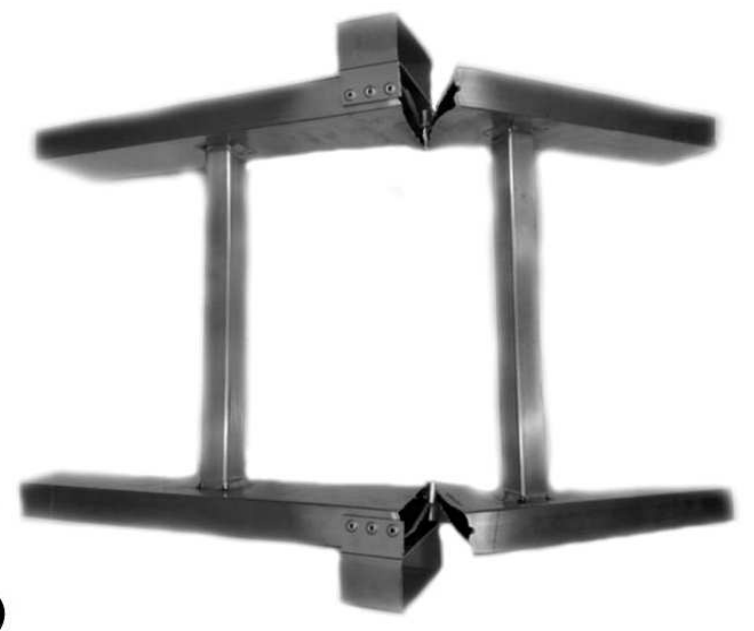

Fig. 4 A detailed insight on the fractured areas of: a) ladder no. 1 with areas used for further examination); b) ladder no. 2
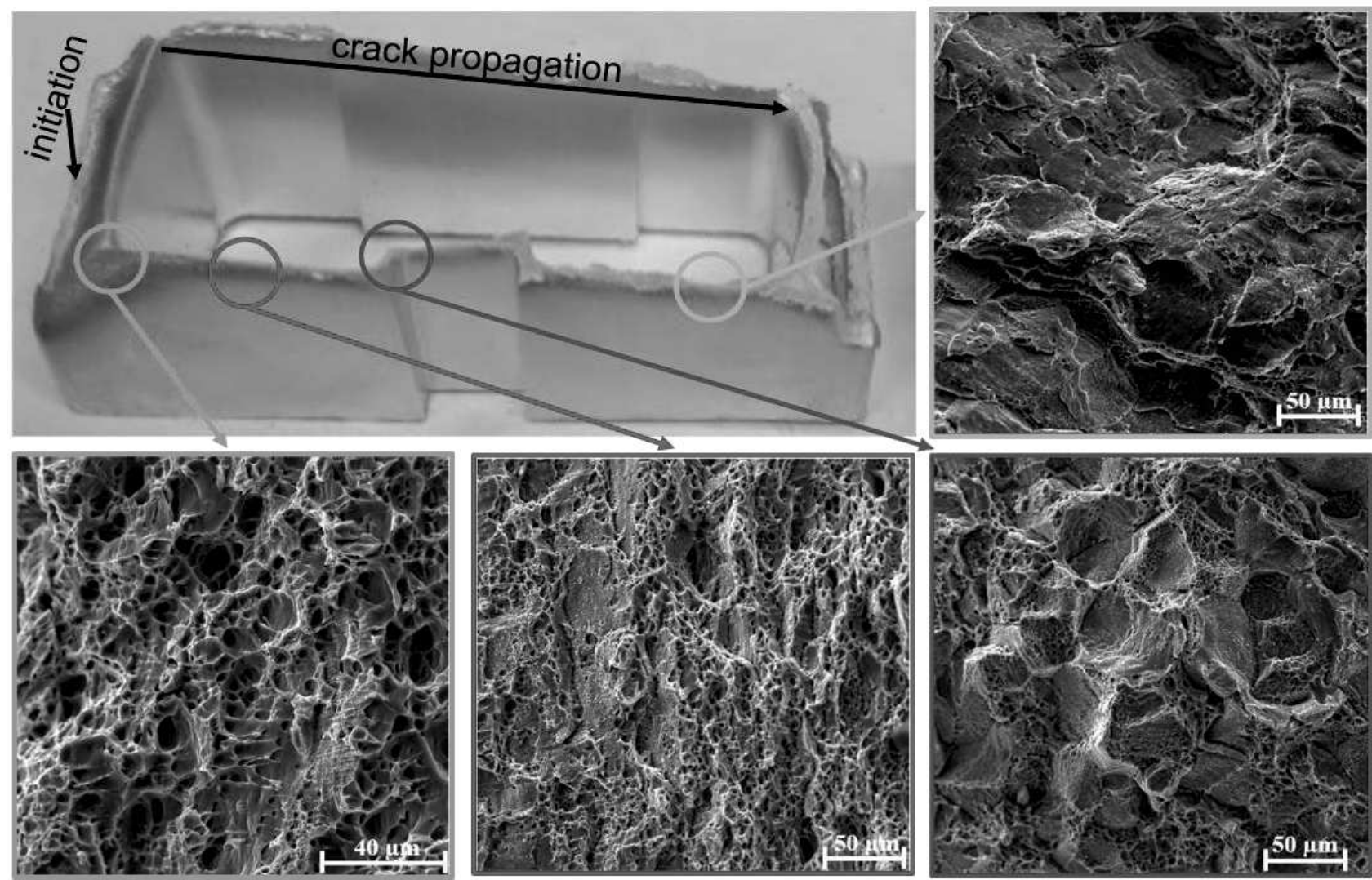

Fig. 5 SEM micrographs of fracture morphology taken on several places on the beam showing changing morphology from ductile to brittle behaviour

Besides, the weld was also investigated for microstructure and hardness distribution along the longitudinal axis of the tested beam as it is marked in Fig. 4a (area A). It was found, that the hardness distribution was highly scattered considering the thermally induced effects during welding of the guide (Fig. 6). The lowest hardness was reached in the guide reaching an average hardness of approximately $58 \mathrm{HV} 1$. Compared, the weld itself reached slightly higher hardness of approximately $62 \mathrm{HV} \mathrm{1,} \mathrm{although} \mathrm{the} \mathrm{results} \mathrm{were}$ showing higher heterogeneity. While continuing from the weld towards the crack site resulted in a sharp hardness increase up to $75 \mathrm{HV} 1$ showing also scattered values. This was caused either by the heterogeneity of the microstructure due to temperature-related effects (grain coarsening, the formation of metastable phases, grain size heterogeneity with strong orientation along the thermal gradient etc.) as well due to a deformation strengthening caused during the test. Also, the deformation strengthening contributed to the overall high heterogeneity of the hardness distribution. 

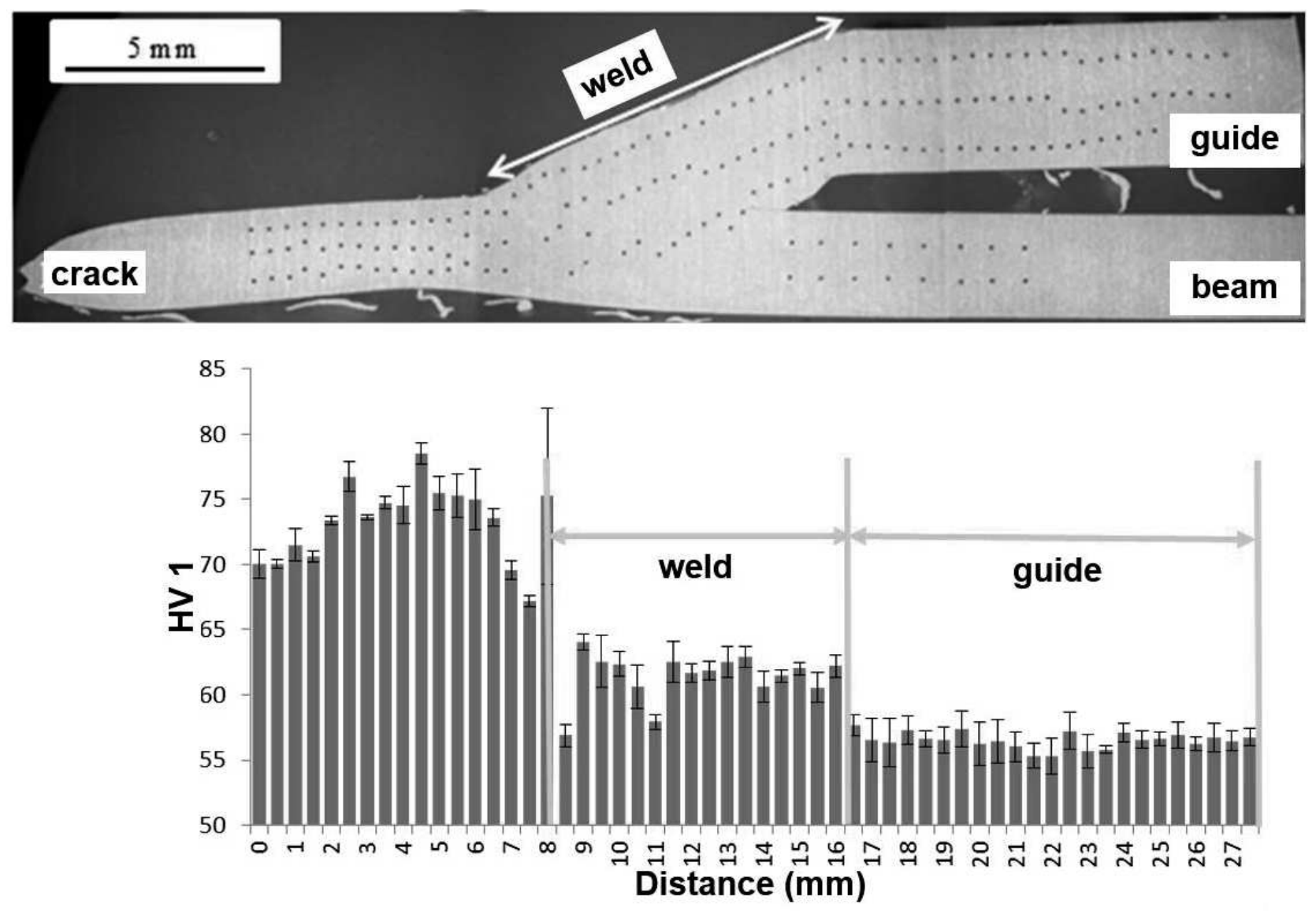

Fig. 6 The hardness HV 1 distribution in the broken ladder along the beam, weld and guide
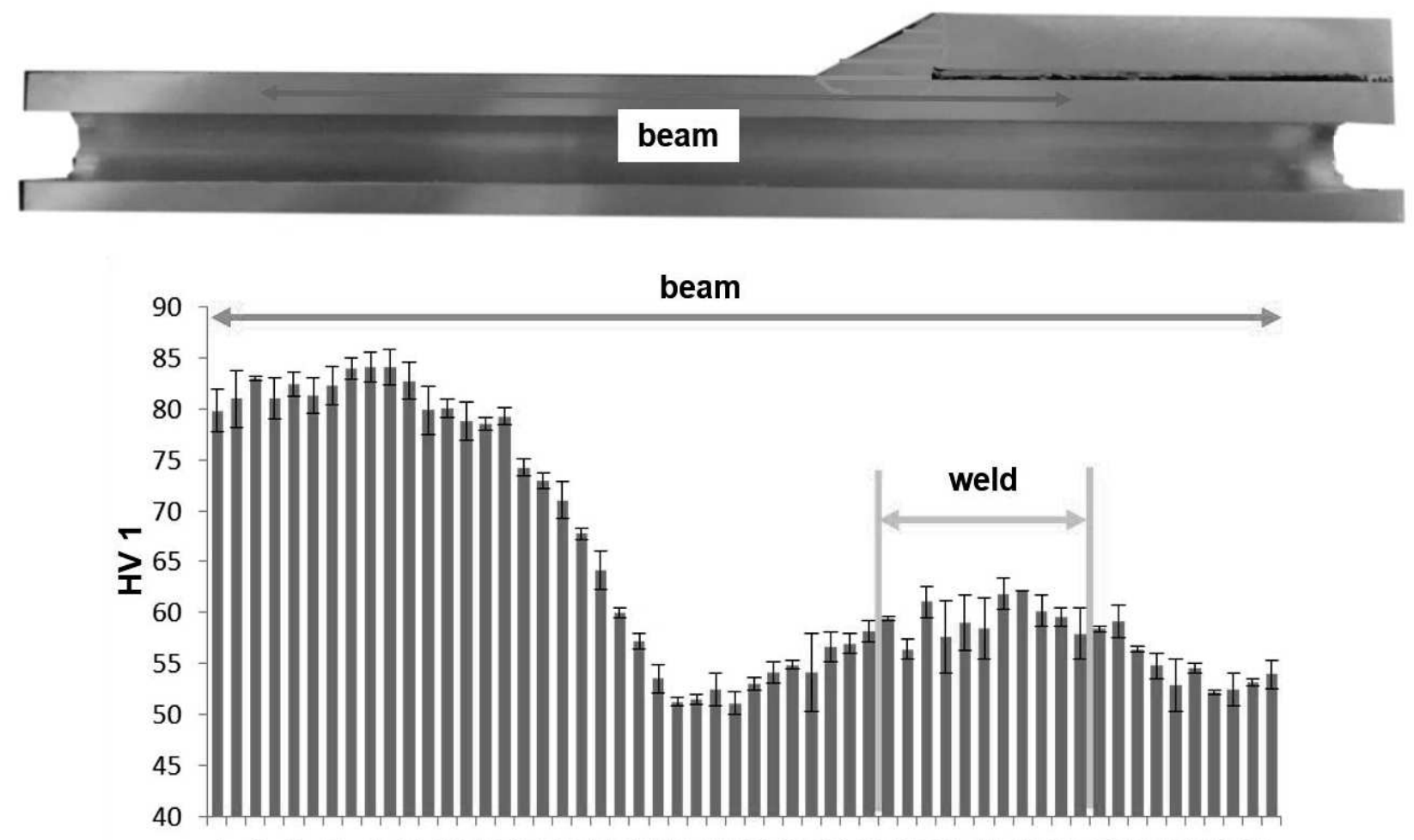

$1357 \quad 7 \quad 91113151719212325272931333537394143454749515355$ Distance $(\mathrm{mm})$

Fig. 7 The hardness HV 1 distribution across the beam showing a heat-affected area nearby the weld 
Thus, the same area was examined on the non-tested part of the ladder to provide complex information about the hardness distributions (Fig. 7). This test was done to determine the hardness profile of the beam since the crack in all the tests initiated and propagated exclusively only throughout the beam. As is shown in Fig. 7, the hardness of the beam was reaching approximately $82 \mathrm{HV}$ 1, which is in good accordance with our previous investigations that proved the beam having a hardness of approximately $78 \mathrm{HBW}$ 2.5/62.5/10 [1]. One can also see, that with the increasing distance from the weld itself, the hardness decreases suggesting that the heat-affected zone was wider than previously thought.

Closer to the weld, we observed a steep hardness decrease starting approximately $19 \mathrm{~mm}$ from the weld bead edge. This decrease reaches its minima of $52 \mathrm{HV}$ 1 in a $10 \mathrm{~mm}$ distance of the weld edge. The observed minimum corresponds to the place of the crack initiation and therefore, the main cause of the significantly lower performance of this ladder is attributed to the thermally affected area of the beam. Since the hardness value can be used as a certain prediction to other properties, it can be assumed that the tensile properties of the beam also decreased significantly. This allows initiating of a crack and its further growth decreasing the active cross-section of the ladder and quick breakage.

As it was already prooved, the thermally affected zone, which exhibited much lower hardness than the rest of the beam, also corresponded with the crack initiation. Thus, the different areas around the weld bead were investigated by the means of $\mathrm{OM}$ as is shown in Fig. 8. The centre of the weld (Fig. 8a) showed a variety of different structures composed of dendritic-like structures which form due to low cooling rates which are typically achieved in the middle of the central parts of the weld. On the other hand, the interface between weld and guide (Fig. 8b) showed on the side adjacent to the weld a presence of fine-grained phases which were substituted by an elongated needlelike phase-oriented in the direction of heat dissipation. Further, towards the right side, a visible texture with grains oriented in the forming direction can be seen. As a comparison, the microstructure of the beam 20 $\mathrm{mm}$ away from the weld was also observed showing presence of recrystallized equiaxed grains which are present in the extruded material. From this point of view, the guide was welded in the as-received state while the beam has undergone a hot-extrusion and artificial ageing which resulted in a formation of equiaxed grains and finely dispersed particles of $\mathrm{Al}(\mathrm{Fe}, \mathrm{Si}) \mathrm{Mn}$ phases as well as by the presence of nanocrystalline $\mathrm{Mg}_{2} \mathrm{Si}$ precipitates which are also reported by others. The presence of these microstructural constituents was confirmed by detailed SEM and TEM investigations, although are not present here.
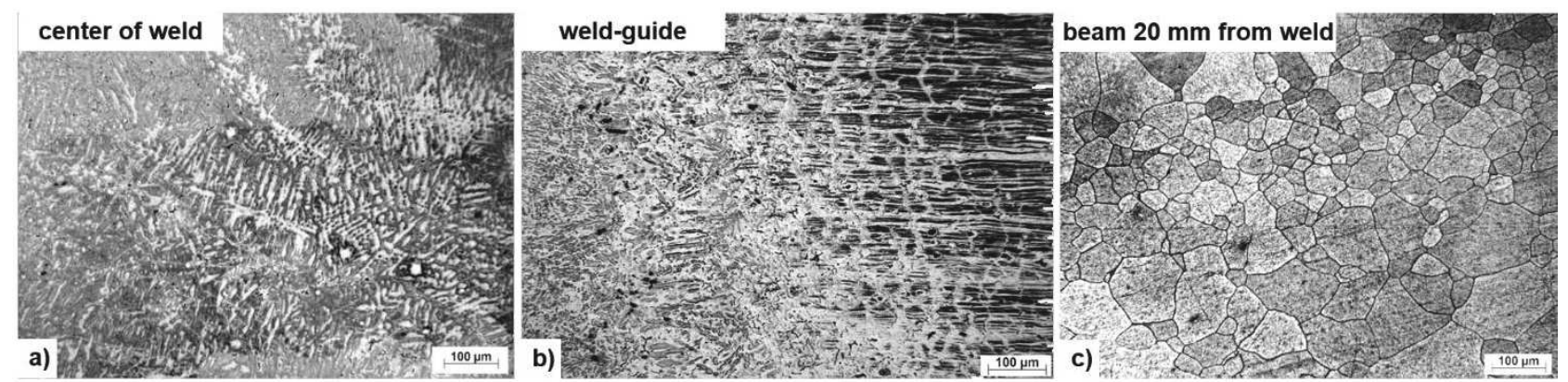

Fig. 8 OM micrographs were taken in: a) the centre of the weld; b) in the area between the weld and guide; c) the beam $20 \mathrm{~mm}$ away from the weld

\section{Conclusion}

Two firefighter ladders were destructively tested to determine their mechanical properties under a steadily increasing load. It was found, that against the presumptions, which favoured the new ladder no. 1 with much complex beam profile, that the mounting of the guides strongly affects the behaviour of the ladder. Ladder no. 1 with welded rivets cracked when loaded with $366(365 \mathrm{~kg})$ and the crack initiated approximately $10 \mathrm{~mm}$ from the weld edge. On the other hand, the 5-year old yet non-used ladder no. 2, which had a simpler beam profile, withstand in the same test much higher load of $426 \mathrm{~kg}$. The main reason for this was found in the design of the guide attachment, which in the case of welded guides deteriorated the properties of the complex beam.

\section{Acknowledgement}

Authors wish to thank the Ministry of Interior (project: Safety improvement of extension ladders for firefighters - VI20162020021) for the financial support of this research.

\section{References}

[1] PRŮŠA, F., KUBÍČKOVÁ, D., JONÁK, V., VESELKA, Z., AND VOJTĚCH, D. (2018). Firefighter ladders made of AA6063 alloy 
exposed to elevated temperatures and its influence onto mechanical properties Manufacturing Technology 2018, 18, 811-816. 10.21062/ujep/180.2018/a/12132489/MT/18/5/811

[2] DÁM, K., PRŮŠA, F., AND VOJTĚCH, D. (2014). Structural and mechanical characteristics of the Al-23Si-8Fe-5Mn alloy prepared by combination of centrifugal spraying and hot die forging Mater. Sci. Eng., A 2014, 610, 197-202. 10.1016/j.msea.2014.05.045

[3] PRŮŠA, F., VOJTĚCH, D., BLÁHOVÁ, M., MICHALCOVÁ, A., KUBATÍK, T.F., AND ČİŽEK, J. (2015). Structure and mechanical properties of Al-Si-Fe alloys prepared by shortterm mechanical alloying and spark plasma sintering Mater. Des. 2015, 75, 65-75. 10.1016/j.matdes.2015.03.016

[4] VOJTĚCH, D., MICHALCOVÁ, A., PRŮŠA, F., DÁM, K., AND ŠEDÁ, P. (2012). Properties of the thermally stable $\mathrm{Al} 95 \mathrm{Cr} 3.1 \mathrm{Fe} 1.1 \mathrm{Ti} 0.8$ alloy prepared by cold-compression at ultra-high pressure and by hot-extrusion Mater. Charact. 2012, 66, 83-92. 10.1016/j.matchar.2012.02.011

[5] PRŮŠA, F. AND VOJTECH, D. (2013). Mechanical properties and thermal stability of Al$23 \mathrm{Si}-8 \mathrm{Fe}-1 \mathrm{Cr}$ and $\mathrm{Al}-23 \mathrm{Si}-8 \mathrm{Fe}-5 \mathrm{Mn}$ alloys prepared by powder metallurgy Mater. Sci. Eng., A 2013, 565, 13-20. 10.1016/j.msea.2012.11.119

[6] KUČERA, V., PRŮŠA, F., AND VOJTĚCH, D. (2017). Al-Fe chips processed by high-energy ball milling and spark plasma sintering, in Solid State Phenomena. 2017. p. 197-204.

[7] VOJTĚCH, D., PRUŠA, F., AND MICHALCOVÁ, A. (2010). Structural and mechanical characterization of rapidly solidified $\mathrm{Al} 95 \mathrm{Ni} 5$ and $\mathrm{Al} 93 \mathrm{Ni} 5 \mathrm{Mm} 2$ alloys prepared by centrifugal atomization J. Alloys Compd. 2010, 506, 581-588. 10.1016/j.jallcom.2010.07.081

[8] PRŮŠA, F., VOJTECH, D., BERNATIKOVÁ, A., AND DVORSKỲ, D. (2015). Mechanical alloying: A way how to improve properties of aluminium alloys Manufacturing Technology 2015, 15, 1036-1043.
[9] DÁM, K., VOJTĚCH, D., AND PRŮŠA, F. (2013). Powder metallurgy Al-6Cr-2Fe-1Ti alloy prepared by melt atomisation and hot ultra-high pressure compaction Mater. Sci. Eng., A 2013, 560, 705-710. 10.1016/j.msea.2012.10.017

[10] ŠKOLÁKOVÁ, A., NOVÁK, P., MEJZLÍKOVÁ, L., PRUŠA, F., SALVETR, P., AND VOJTÉCH, D. (2017). Structure and mechanical properties of $\mathrm{Al}-\mathrm{Cu}-\mathrm{Fe}-\mathrm{X}$ alloys with excellent thermal stability Materials 2017, 10, $10.3390 / \mathrm{ma} 10111269$

[11] KUCERA, V., PRUSA, F., AND VOJTECH, D. (2017). Aluminium alloys with transition metals prepared by powder metallurgy. in IOP Conference Series: Materials Science and Engineering. 2017.

[12] PRŮŠA, F., KUČERA, V., AND VOJTĚCH, D. (2017). An Al-17Fe alloy with high ductility and excellent thermal stability Mater. Des. 2017, 132, 459-466. 10.1016/j.matdes.2017.07.027

[13] KUČERA, V. AND VOJTĚCH, D. (2017). Influence of the heat treatment on corrosion behaviour and mechanical properties of the AA 7075 alloy Manufacturing Technology 2017, 17, 747 752.

[14] ŠKOLÁKOVÁ, A., NOVÁK, P., VOJTĚCH, D., AND KUBATÍK, T.F. (2014). Production of Al-Si-Fe-X alloys by powder metallurgy Manufacturing Technology 2014, 14, 437-441.

[15] KUCERA, V., PRŮŠA, F., AND VOJTĚCH, D. (2016). Processing of aluminium alloys with high content of iron by methods of powder metallurgy Manufacturing Technology 2016, 16, 978-984.

[16] ŠKOLÁKOVÁ, A., HANUSOVÁ, P., PRŮŠA, F., SALVETR, P., NOVÁK, P., AND VOJTĚCH, D. (2018). Microstructure and thermal stability of Al-Fe-X alloys Acta Metallurgica Slovaca 2018, 24, 223-228. 10.12776/ams.v24i3.1106

[17] KUBASEK, J., VOJTECH, D., AND DVORSKY, D. (2017). Structure and Mechanical Properties of Aluminium Alloy Sampled from a Firefighter Ladder Manufacturing Technology Journal 2017, 17, 876-881. 10.21062/ujep/x.2017/a/12132489/MT/17/6/876 